\title{
Scope to Maximise Rice Yellow Stem Borer Moth Catch in Delta Type Pheromone Traps
}

\author{
Raga Palanisamy Soundararajan ${ }^{1}$, Gnanadas Preetha ${ }^{1}$, Amirtharaaj Vijayashanthi, \\ Mannarsamy Prabakaran ${ }^{2}$, Srinivasan Sithanantham ${ }^{3,}$, Kunchithapatham Ramaraju ${ }^{1}$, \\ Narayanan Muthukrishnan ${ }^{1}$ \\ ${ }^{1}$ Department of Agricultural Entomology, Tamil Nadu Agricultural University, Coimbatore, India \\ ${ }^{2}$ Laksitha Agro Biotech, Mugalivakkam, Chennai, India \\ ${ }^{3}$ Sun Agro Biotech Research Centre, Mugalivakkam, Chennai, India
}

\section{Email address:}

sound73insect@gmail.com (R. P. Soundararajan), gpreetha@gmail.com (G. Preetha), vijaya_amir@yahoo.com (A. Vijayashanthi), prabakaranbio07@gmail.com (M. Prabakaran), sithanantham@yahoo.com (S. Sithanantham), sabrcchennai@yhaoo.co.in (S. Sithanantham), kunchiramaraju@yahoo.com (K. Ramaraju),nmkrish@tnau.ac.in (N. Muthukrishnan)

${ }^{*}$ Correspondence author

\section{To cite this article:}

Raga Palanisamy Soundararajan, Gnanadas Preetha, Amirtharaaj Vijayashanthi, Mannarsamy Prabakaran, Srinivasan Sithanantham, Kunchithapatham Ramaraju, Narayanan Muthukrishnan. Scope to Maximise Rice Yellow Stem Borer Moth Catch in Delta Type Pheromone Traps. American Journal of Entomology. Vol. 4, No. 4, 2020, pp. 58-65. doi: 10.11648/j.aje.20200404.11

Received: October 13, 2020; Accepted: October 29, 2020; Published: November 23, 2020

\begin{abstract}
The yellow stem borer (YSB), Scirpophaga incertulas (Walker), is a major pest of rice in Asia and pheromone trapping technology is emerging as a promising eco-friendly IPM tool for more sustainably managing this pest. To identify more efficient trap design so to maximize the efficiency of attracting and retaining the male moths in pheromone-based trapping system, a common methodology-based network study was taken up to compare the moth catches in alternative sex pheromone-baited Delta traps of varying attributes versus the commonly used Funnel (sleeve) trap at three major rice growing locations (Coimbatore, Tirurkuppam, Tirupathisaram) in Tamil Nadu, India within the same season during 2017-18. The results from the concurrent six week trap catch studies clarified that two superior Delta trap variants caught significantly more YSB moths than the funnel trap at all three locations. The moth catches were about 4-5 times greater in the normal size Delta trap $(32 \times 20 \times 11 \mathrm{~cm})$ compared the Funnel traps, while even the smaller size Delta trap $(22 \times 12 \times 7.5 \mathrm{~cm})$ caught nearly 2 times more moths than Funnel traps. The attribute of additional vents on the side roof of Delta traps was found to enhance the moth catch in Delta trap significantly. The relative moth catches among the five Delta trap variants versus Funnel trap at each location are also illustrated, along with results of pooled analysis over the locations, which confirmed the consistent superiority of Delta trap versions and the extra benefit from additional vents as trap attributes in enhancing the moth catches. The present results have shown the scope to enhance the impact potential of the improved Delta trap designs in monitoring and mass-trapping of YSB. The need for future population ecology R\&D in linking the use of such improved Delta trap versions to fine-tuning the local action thresholds which are based on trap catches by relating to trapping efficiency as a factor is indicated.
\end{abstract}

Keywords: Pheromone Trap, Rice Yellow Stem Borer, Delta Trap, Funnel Trap, Trapping Efficiency

\section{Introduction}

Yellow stem borer (YSB), Scirpophaga incertulas (Walker) (Crambidae: Lepidoptera) is a major insect pest in all rice growing regions of Asia [1] and reckoned as the prime devastating rice pest causing 10-60 percent loss across India
[2]. The YSB female sex pheromone was identified as 3:1 ratio blend of (Z)-11-hexadecenal plus (Z)-9- hexadecenal [3] and the usefulness of YSB sex pheromone-based traps as monitoring tool in rice ecosystems has been well documented [4-11], with potential for pheromone trapping as IPM component for YSB $[12,13]$. The scope for pheromone- 
based mass trapping of YSB as a promising also component of IPM in India has also been well recognized [14-17]. In the Tamil Nadu state of India, studies on YSB have been made on the seasonality on YSB [18], whereas the testing of alternative pheromone trap designs to the locally adopted Funnel traps has not been taken up. The present study was undertaken collaboratively to evaluate five Delta trap variants compared with Funnel trap for YSB moth catches in three rice growing regions of Tamil Nadu, India.

\section{Materials and Methods}

The locations for the present study were three research stations of the Tamil Nadu Agricultural University (TNAU), namely Coimbatore, Tirurkuppam and Thirupathisaram, located in different agro-ecozones of Tamil Nadu, India. The locations map is given in Figure 1, while the GPS parameters and rainfall data are summarized in Table 1.

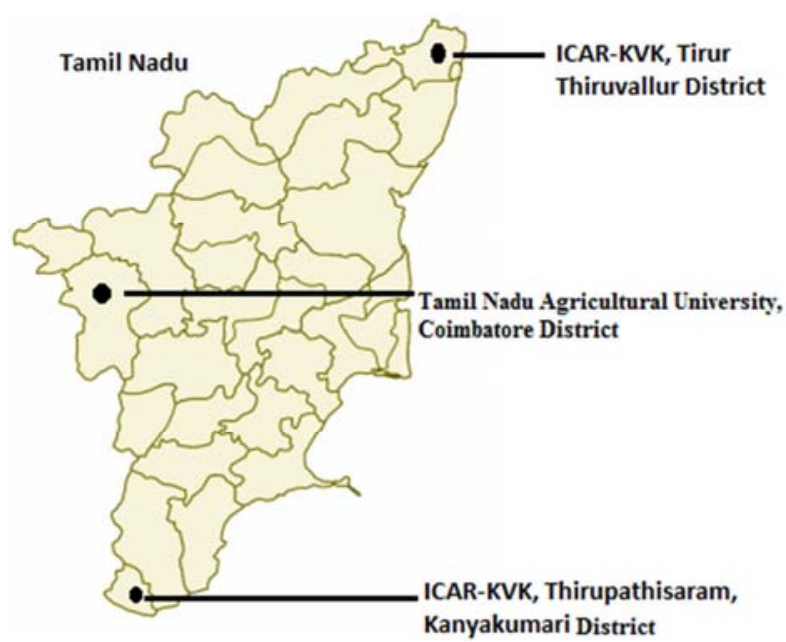

Figure 1. Locations of the pheromone trap studies in Tamil Nadu.

Table 1. Geoposition and rainfall pattern for the three trial locations in Tamil Nadu, India.

\begin{tabular}{|c|c|c|c|c|}
\hline Locations (Affiliation) & Altitude & Latitude & Longitude & Seasonal Rain fall (mm) \\
\hline Main campus, Coimbatore (Tamil Nadu Agricultural University) & $432.05 \mathrm{~m}$ & $11^{\circ} 00^{\prime} \mathrm{N}$ & $77^{\circ} 00^{\prime} \mathrm{E}$ & 20.20 \\
\hline Tirurkuppam (TNAU-Krishi Vigyan Kendra, Thiruvallur District) & $43.98 \mathrm{~m}$ & $13^{\circ} 09^{\prime} \mathrm{N}$ & $79^{\circ} 57^{\prime} \mathrm{E}$ & 69.74 \\
\hline Thirupathisaram (TNAU-Agricultural Research Station, Kanyakumari District) & $36.21 \mathrm{~m}$ & $8^{\circ} 11^{\prime} \mathrm{N}$ & $77^{\circ} 29^{\prime} \mathrm{E}$ & 45.80 \\
\hline
\end{tabular}

The rice crop grown for the field trial at Coimbatore was during Jan - Mar 2018, at Tirurkuppam during Dec 2017-Feb 2018 and in Feb - Apr 2018 at Thirupathisaram. The rice crop grown without insecticidal protection in about one acre $(0.4$ hectare) in extent and about 3-4 weeks age after transplanting was divided into four replications laid out in Randomized Block design (RBD) to compare the six trap design treatments described below:

$\mathrm{T}_{1}$. Delta-normal size -with four circular vents (each of 2.5-cm dia.)

$\mathrm{T}_{2}$. Delta-normal size $(32.0 \times 20.0 \times 11.0 \mathrm{~cm})-$ no additional vents

$\mathrm{T}_{3}$. Delta-normal size-with two rectangular vents (each of $13.0-\mathrm{x} 3.0 \mathrm{~cm}$.)
$\mathrm{T}_{4}$. Delta-smaller size- with four circular vents (each of 2.5-cm dia.)

$\mathrm{T}_{5}$. Delta-smaller size $(22.0 \times 12.0 \times 7.5 \mathrm{~cm})$ - no additional vents

$\mathrm{T}_{6}$. Funnel trap- (hood-14.3cm.dia; funnel rim-11.5cm.dia; bottom hole dia. $3.0 \mathrm{~cm}$ )

The synthetic sex pheromone blend of (Z)-11-hexadecenal plus (Z)-9- hexadecenal) in 3:1 ratio was obtained from BioControl Research Laboratory (BCRL), Bengaluru, India and formulated as lure in standard rubber septa impregnated with the pheromone (3mg) at Sun Agro Biotech Research Centre, Chennai, India. The illustration of the different pheromone trap types compared is furnished in Figure 2.

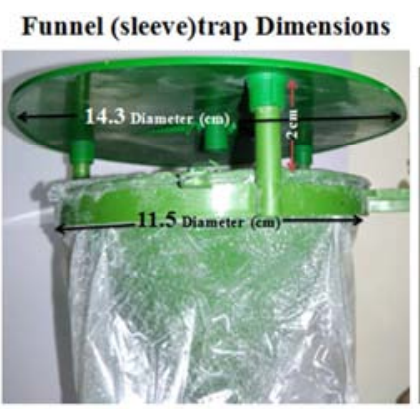

Delta trap with access window

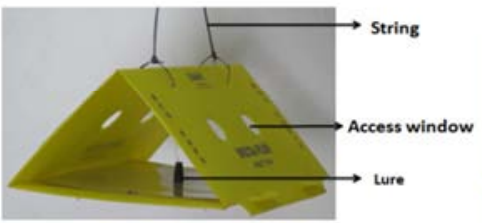

Funnel Trap

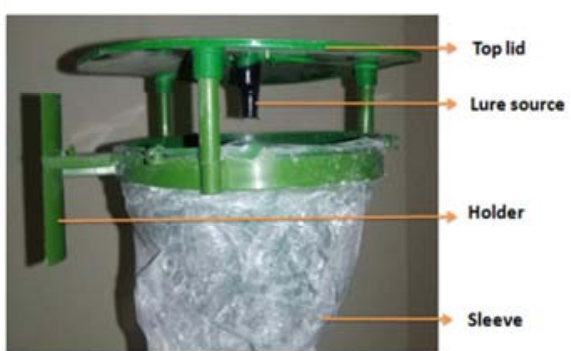

Delta trap without access window

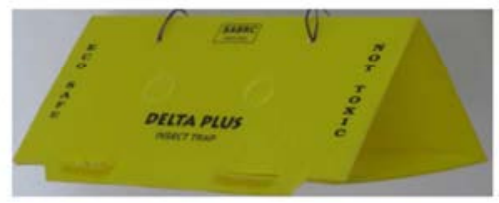


Delta Normal Size Dimensions

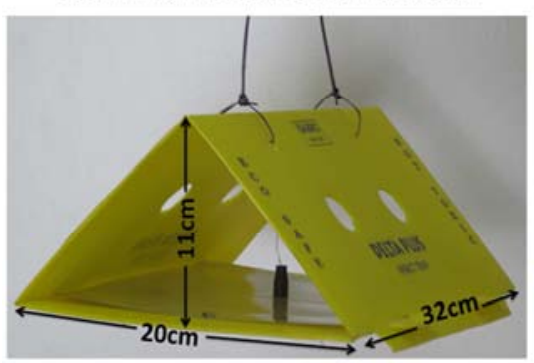

Delta trap Sizes

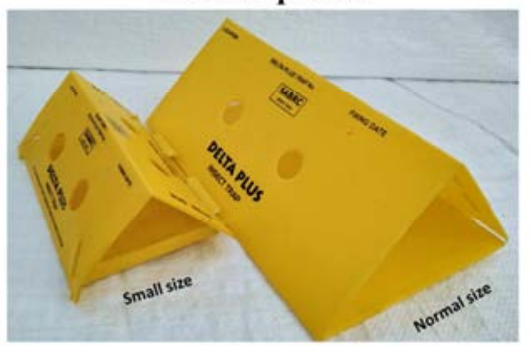

Trapped moths in sticky arena view

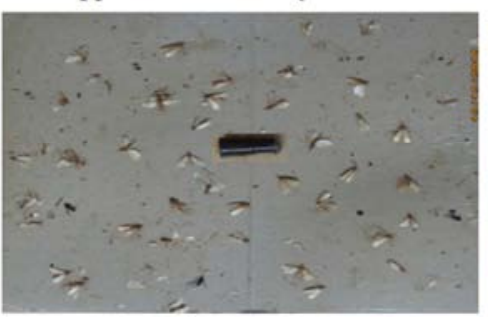

\section{Delta Small Size Dimensions}

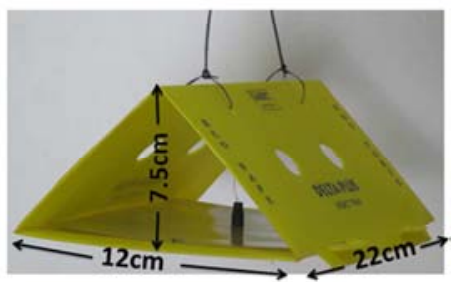

Two Sticky Arena Sizes

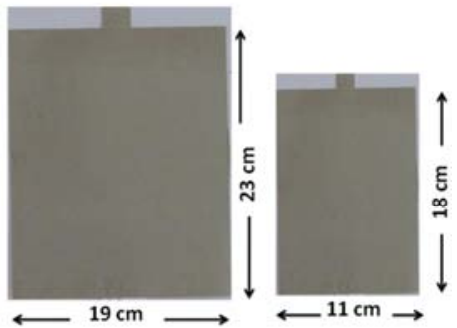

Trap comparison field view

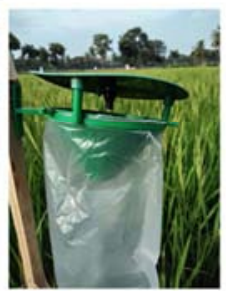

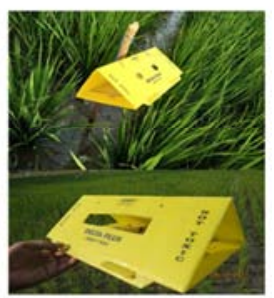

Figure 2. Pheromone trap types compared and their attributes-dimensions.

Each replication was assigned about 0.10 ha area. The treatments within each replication were located at an inter distance of ten metres. The positions of treatments within each replication were kept at random initially and further inter-changed randomly after each successive week of moth catch observation, so to minimise position effects on trap catches. The rectangular sticky liners for the Delta traps normal size $(23 \times 19 \mathrm{~cm})$ and smaller size $(18 \times 11 \mathrm{~cm})$ - were replaced weekly, after recording the weekly catches for five successive weeks.

The data on weekly moth catches in the traps were subjected to ANOVA as per the statistical methods described [19].

\section{Experimental Results}

\section{Location 1: Coimbatore}

The results of ANOVA are summarised in Table 2 which showed that moth catches differed significantly among the treatments, besides among the five weeks, while interaction between treatments and weeks was not significant.

Table 2. Results of ANOVA of pheromone trap catches at Coimbatore.

\begin{tabular}{llll}
\hline & Significance Level & CD (0.05) Value & F-Value \\
\hline Treatments & $* *$ & 1.55 & 11.84 \\
Weeks & $* *$ & 1.41 & 4.15 \\
Treatments X Weeks & NS & NA & 1.12 \\
\hline
\end{tabular}

$* *=$ Significant at $\mathrm{p}=0.01 ; \mathrm{NS}=$ Not significant; NA=Not applicable.

The overall moth catch was 2.48 per week, with a range of 1.79 to 4.29 across the six weeks. Compared to the mean catch of 2.05 moths in Funnel traps, the Delta trap of normal size with circular vents recorded significantly higher catch (6.25), while the other Delta variants were all on par with Funnel trap (Figure 3). 


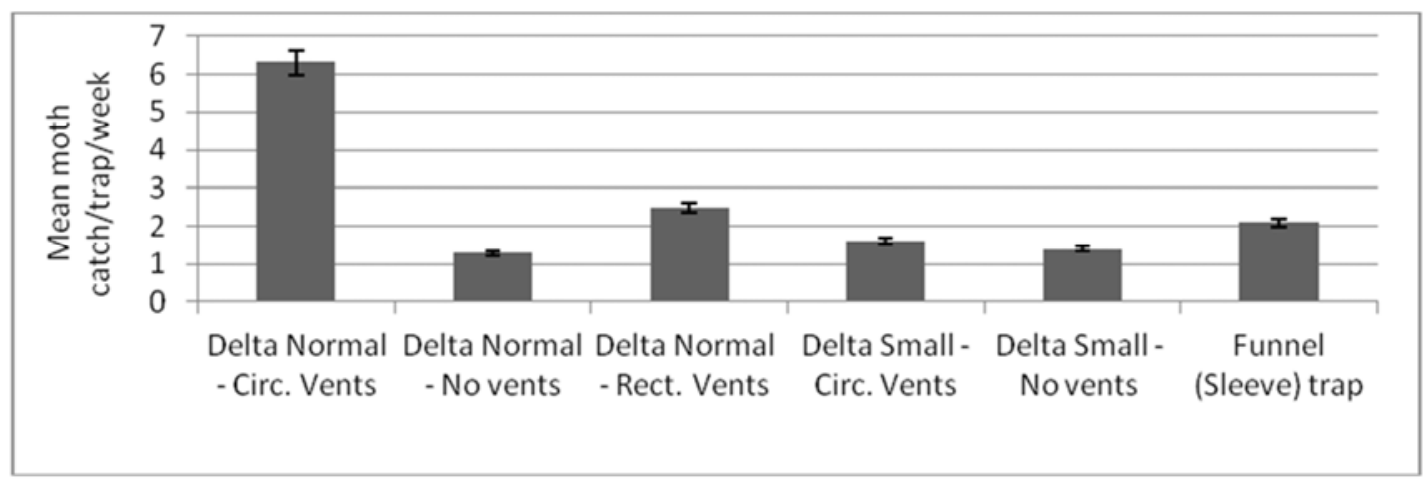

Figure 3. Mean catches of YSB moths in different trap treatments at Coimbatore.

The overall increase in moth catch in Delta normal with circular vents (T1) was about 205\% over the Funnel trap (T6).

Further, the weekly moth catch in the best Delta variant (T1) was consistently higher than in the Funnel trap (T6) in all the five weeks of study, as illustrated in Figure 4.

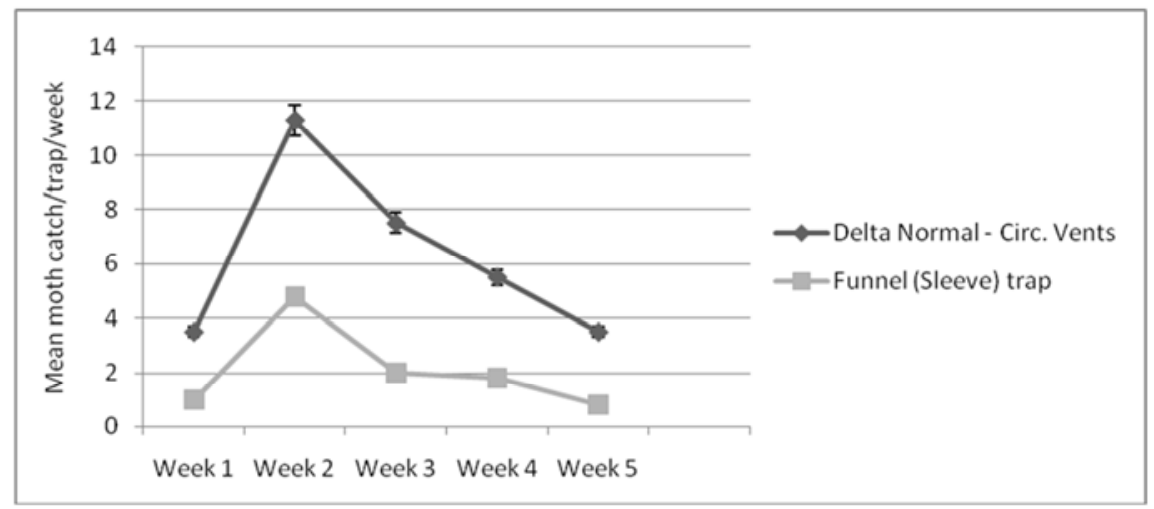

Figure 4. Weekly pattern of moth catches in one Delta variants and funnel trap at Coimbatore.

Location 2: Tirurkuppam

In this location also the treatments differed significantly, besides among the six weeks and their interaction was also significant as summarized in Table 3.

Table 3. Results of ANOVA of pheromone trap catches at Tirurkuppam.

\begin{tabular}{llll}
\hline & Significance Level & CD (0.05) Value & F-Value \\
\hline Treatments & $* *$ & 2.51 & 32.37 \\
Weeks & $* *$ & 1.77 & 26.62 \\
Treatments X Weeks & $* *$ & 5.61 & 3.88 \\
\hline
\end{tabular}

$* *=$ Significant at $\mathrm{p}=0.01 ; \mathrm{NS}=$ Not significant; $\mathrm{NA}=$ Not Applicable

The mean moth catch per week averaged 6.78, while the range was 2.03 to 10.13 across the six week period. Three normal size variants of Delta traps recorded significantly higher catches ranging between 12.25 and 17.70 , compared to 3.40 months in Funnel traps (Figure 5).

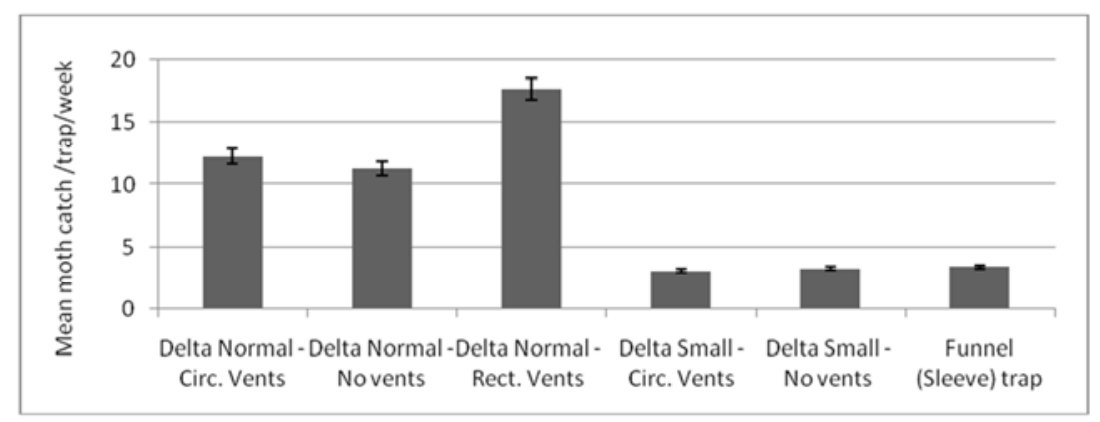

Figure 5. Mean catches of YSB moths in different trap treatments at Tirurkuppam. 
The overall percent increase in moth catches for the Delta trap normal size variants, namely with circular vents (T1), without vents (T2) and with rectangular vents (T3) over the funnel trap (T6) was $260 \%, 222 \%$ and $421 \%$, respectively.

The weekly moth catches in T1, T2 and T3 were mostly consistent for higher moth catches than T6 over the six week period of study. (Figure 6)

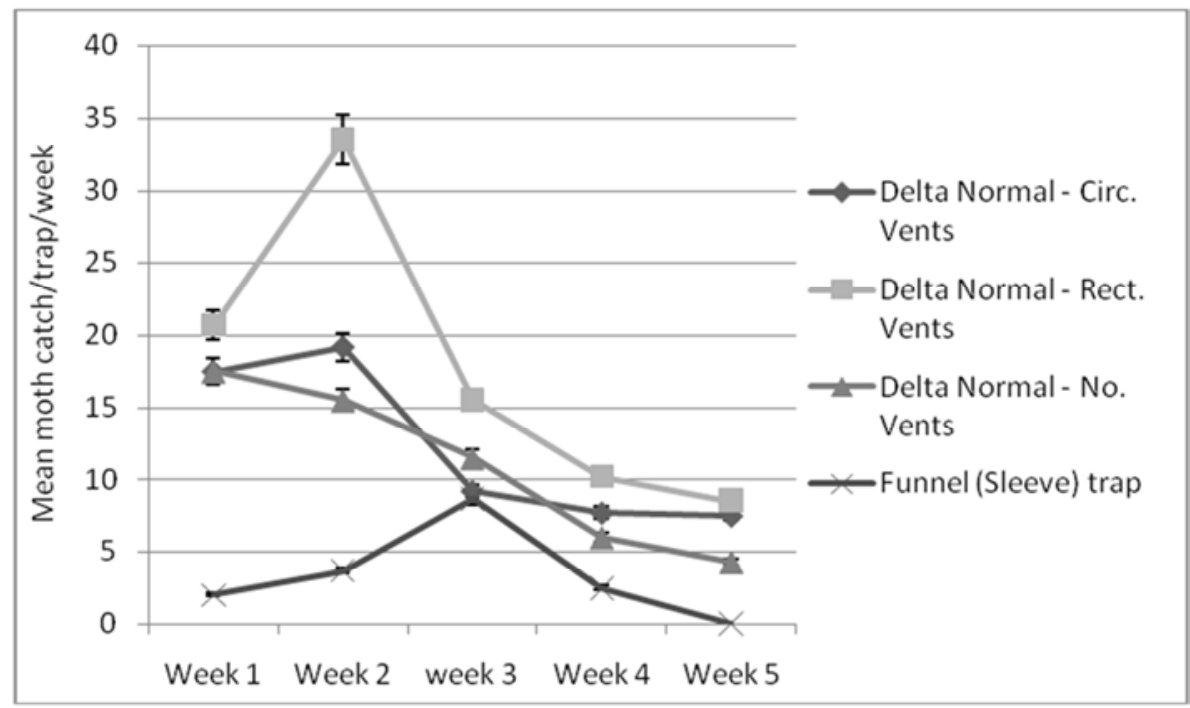

Figure 6. Weekly pattern of moths catches in three superior Delta trap variants at Tirurkuppam.

Location 3: Thirupathisaram

In this location also there were significant differences among the six treatments and also the six weeks, besides their significant interaction and the results of ANOVA are summarised in Table 4.

Table 4. Results of ANOVA of pheromone trap catches at Thirupathisaram.

\begin{tabular}{llll}
\hline & Significant & CD (0.05) Value & F-Value \\
\hline Treatments & $* *$ & 6.91 & 23.55 \\
Weeks & $* *$ & 6.31 & 48.42 \\
Treatments X Weeks & $*$ & 15.45 & 2.72 \\
\hline
\end{tabular}

**=Significant at $\mathrm{p}=0.01 ; *=$ Significant at $\mathrm{p}=0.05 ; \mathrm{NS}=$ Not significant; $\mathrm{NA}=$ Not Applicable.

The overall moth catch per week was the highest (21.45 moths) compared to other locations, with weekly catch range of 1.08 to 37.88 moths. Compared to the overall catch of 2.50 moths in Funnel traps, all the five variants of Delta traps recorded significantly higher catches ranging between 14.95 and 32.70 (Figure 7).

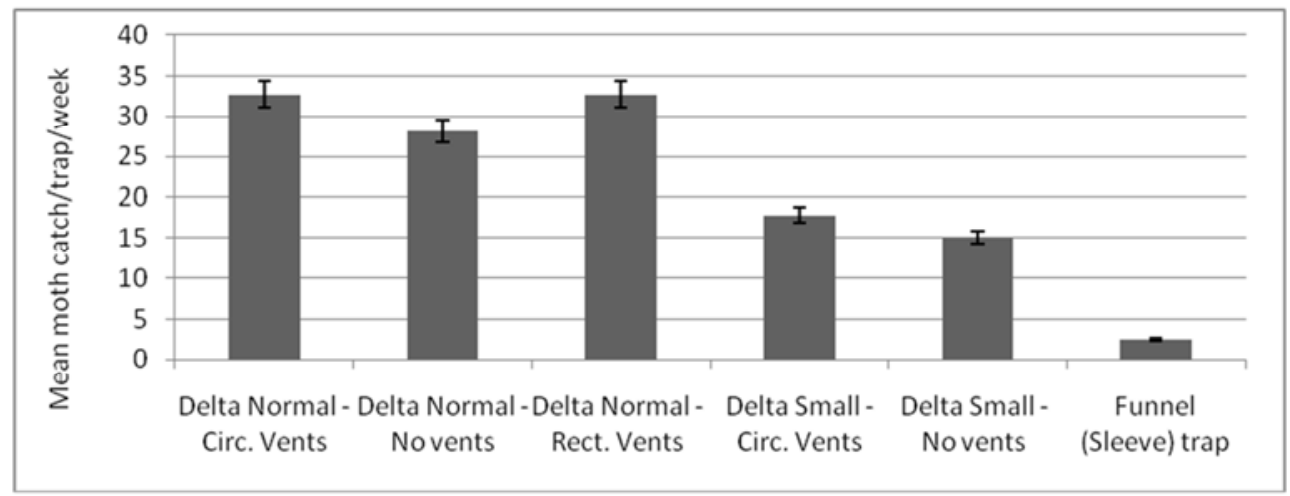

Figure 7. Mean catches of YSB moths in different treatments at Thirupathisaram.

The overall percent increase in moth catches for the Delta trap variants over Funnel trap (T1) was found to be 1184\% in T1, $1024 \%$ in T2, $1208 \%$ in T3 followed by $610 \%$ in T4 and $498 \%$ in T5.

The weekly trend of moth catches (Figure 8) in the three superior Delta variants (T1, T2, T3) recorded consistently higher in catches in all the four weeks compared to the low catches (below 10) for Funnel traps. 


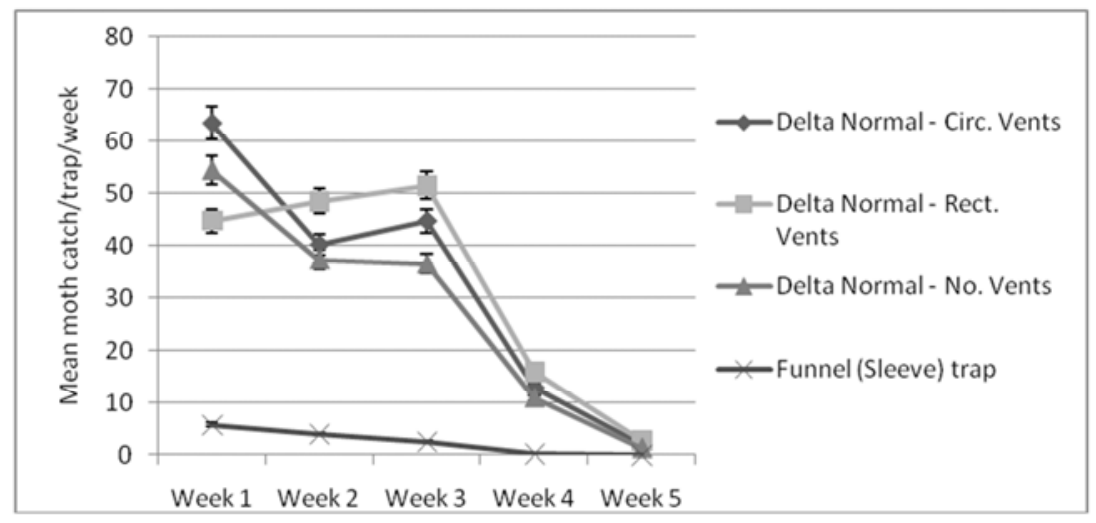

Figure 8. Weekly pattern of moth catches in three promising Delta treatments at Thirupathisaram.

\section{Overall Trend over Three Locations}

The pooled data over the three locations showed an average catch of 10.5 per week, with overall weekly range between 2.1 and 16.8 moths. The treatments also differed significantly (Table 5).

Table 5. Pooled ANOVA of pheromone trap catches in the three locations studied.

\begin{tabular}{llll}
\hline & Significance Level & CD (0.05) Value & F-Value \\
\hline Treatments & $* *$ & 4.70 & 11.83 \\
Weeks & $* *$ & 4.29 & 17.28 \\
Treatments X Weeks & NS & NA & 0.97 \\
\hline
\end{tabular}

$* *=$ Significant at $\mathrm{p}=0.01 ; \mathrm{NS}=$ Not significant; NA=Not applicable.

Compared to the overall catch of 2.65 moths in funnel traps, all the different Delta trap variants recorded significantly higher overall moth catches ranging between 6.52 and 17.23 (Figure 9).

The overall percent increase in moth catches for the Delta trap variants over the funnel trap was found to be maximum
$(550 \%)$ in normal size Delta trap with four circular access vents (T1), but it was on par with the other two Delta variants in the same size (T2, T3), which recorded overall increase in catch by $406 \%$ and $498 \%$ respectively, while the two variants in smaller size delta trap showed also overall increase in moth catches only by 146 and $182 \%$.

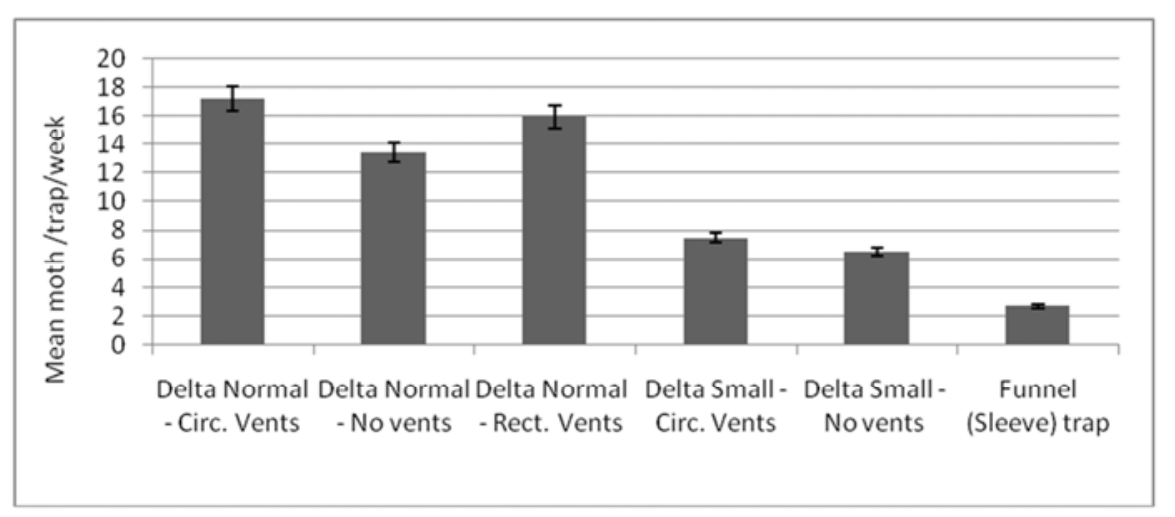

Figure 9. Overall YSB moth catch pooled over three locations comparing the trap types.

\section{Comparisons of Delta Trap Attributes}

\subsection{Two Sizes of Delta Trap}

The overall moth catches when pooled over the variants with and without circular vents, comparing normal size Delta versus small size Delta were15.3 and 7.0, respectively, the normal size Delta catching about 119 per cent more moths than small size Delta. Evidently, the normal size Delta trap could catch more than double the number of YSB moths compared to the small size version of Delta trap.

\subsection{Benefit of Circular Vents}

As overall comparison, the attribute of additional circular vents was found to increase the moth catch in both normal and small size Delta traps, by about 28 and 15 per cent respectively.

\subsection{Circular Versus Rectangular Vents}

The relative overall increase in moth catch for circular vents 
was greater than with the rectangular vent, the improvement over Funnel traps being 537 and 488 per cent, respectively.

\section{Discussion}

The major finding in the present study is that the YSB moth catch in pheromone traps could be significantly increased with Delta traps as an alternative to the presently commonly used Funnel (sleeve) type traps. This information is significant in the context of Funnel traps having been earlier recommended for monitoring YSB [20], which were later shown to be less efficient than the water-basin trap [21], which again has been subsequently found to be not so userfriendly [22]. Concurrent studies on pheromone trap designs on another Crambid moth, the early shoot borer of sugarcane, Chilo infuscatellus identified Delta trap being superior to both these trap types [23]. Nevertheless, the present results are the first report of Delta traps being more efficient than Funnel traps in pheromone-based trapping of YSB moths.

Further, the mechanisms by which the two Delta trap attributes, namely trap catch arena size and presence of additional access vents, contribute to more efficient trapping of YSB moths, require further study, for their role in improving the moth arrivals and/or retention in traps, with focus on moth flight and close range escape behaviour, as studied in another Crambid moth - Leucinodes orbonalis in egg plant (brinjal) ecosystem [21, 24]. Between the two sizes of Delta traps studied, the overall moth catch in normal size Delta (with circular vents) was 17.2 versus 7.5 moths in smaller size Delta ( with same attributes), and the normal size Delta trap was also more cost-effective, based on relative price and the moth catch per rupee invested. This trend is comparable to relative sticky arena area size benefits in Delta trap observed for Chilo infuscatellus [23].

There is also scope for more holistic characterization of the role of additional access vents (two on either side) as the other beneficial attribute in Delta trap, especially since both circular and rectangular shape vents were found to significantly improve the moth catch in normal size Delta traps. There is scope to ascertain if such beneficial impact of vents could be due to creating more exit points for the pheromone plumes from the lure source and /or providing more entry points for the attracted moths into the trap. Of course, the presently observed overall benefit of the access vents is in conformity to similar results on Delta trap attributes in trapping Chilo infuscatellus [23] The improved user-friendliness of Delta traps by avoiding frequent water replacement needed in water basin traps could enhance the adoption potential among farmers, assuming that replacing the sticker sheets in Delta traps being lees frequent and not so laborious compared to water basin traps.

Further, since a presently recommended action threshold based on YSB moth catches in pheromone traps is about 25 moths per trap per week [24] which is apparently based on moth catch estimates correlated from Funnel trap, there is scope for locally refining the applicable threshold for moth catches if Delta traps are used, to factor in the differential moth catch efficiency. Further, since past estimates of economic benefit of pheromone-based mass trapping technology were apparently made with Funnel traps [13], there is scope to improve the cost competitiveness of mass trapping of YSB moths as an option, since replacing with Delta variants would obviously be both more efficient and only slightly costlier than Funnel trap, since similar benefit has been shown in the case of another Crambid- the sugarcane early shoot borer [26]. The present results have therefore opened up the good potential for trap design choice as a factor in promoting pheromone-based mass trapping strategy as promising eco-safe alternative to the use of synthetic chemical insecticides for YSB management.

\section{Conclusion}

The present network study has demonstrated the potential for enhancing the YSB moth catches, based on the significant and consistent superiority of Delta trap variants compared to the hitherto commonly used Funnel traps. Further, the relative benefits of two trap design attributes, namely trap size and presence of access vents, in contributing to the YSB moth catch numbers have also been ascertained. It is recommended that the superior Delta trap variants should be utilized in future monitoring programs with suitable refinements in action threshold. Such improved trap designs should also be availed for more cost-effective enhancement of the mass trapping impact and so promote their potential as safer alternative to chemical insecticide use in rice ecosystems. It is visualized that such trap design improvements can leverage the utility of pheromone-based trapping technology as key component in IPM of YSB.

\section{Acknowledgements}

Grateful thanks are extended to the Directorate of Research, Directorate of Plant Protection Studies and the concerned Heads of TNAU research stations at Coimbatore, Tirurkuppam and Thirupathisaram for kindly facilitating the research trials under the ongoing TNAU- MoU collaborative R\&D program with Sun Agro Biotech Research Centre.

\section{References}

[1] Cohen, M. B., M. Romena and F. Gould. 2000. Dispersal by larva of the stem borers Scirpophaga incertulas (Walker) (Lepidoptera; Pyralidae) and Chilo suppresalis (Walker) (Lepidoptera; Pyralidae) in plots of transplanted rice. Environ. Entomol. 29: 958-971.

[2] Chatterjee, S. and P. Mondal. 2014. Management of rice yellow stem borer, Scirpophaga incertulas Walker, using some biorational insecticides. J. Biopest. 7: 143-47.

[3] Cork, A., P. S. Beevor, D. R. Hall, B. F. Nesbitt, G. S. Arida and B. Mochida. 1985. Components of the female sex pheromone of the yellow stem borer Scirpophaga incertulas (Walker). Entomol. Exp. et Applic. 37: 149-153. 
[4] Varma, N. R. G., K. Krishnaiah, I. C. Pasalu and D. D. Reddy. 2000. Monitoring of rice yellow stem borer, Scirpophaga incertulas (Walker) using pheromone trap and thermal summations. Indian J. Plant Prot. 28: 84-93.

[5] Katti, G., I. C. Pasalu, N. R. G. Varma and N. Dhandapani. 2001. Quantification of natural biological control in rice ecosystem for possible exploitation in rice IPM. Indian $J$. Entomol. 63: 439-448.

[6] Varma, N. R. G., K. Krishnaiah, I. C. Pasalu and P. R. M. Rao. 2004. Influence of field size in management of yellow stem borer (YSB), Scirpophaga incertulas Walker through pheromone mediated mass trapping in rice. Indian. J. Plant. Protec. 32 (1): 39-41.

[7] Mahal, M. S., P. S. Sarao and Vinay Kajal. 2011. Evaluation of management techniques for the control of insect-pests of Basmati rice in Punjab. Oryza. 48: 238-243.

[8] Mishra, M. K., R. C. Sharma, R. B. Singh and R. P. Singh. 2012. Monitoring of yellow stem borer, Scirpophaga incertulas (Walker) in rice through light and pheromone traps. Agri. \& Biol. Research. 28 (2): 135-139.

[9] Chatterjee, S., I. Dana, C. Gangopadhyay and C. P. Mondal. 2017. Monitoring of yellow stem borer, Scirpophaga incertulas (Walker) using pheromone trap and light trap along with determination of field incidence in kharif rice. J. Crop and Weed. Sci. 13: 156-159.

[10] Pallavi, D., Sharanabasappa and P. Megaladevi. 2018. Seasonal fluctuation of yellow stem borer, Scirpophaga incertulas (Walker) on paddy and its relationship between trap catches with weather parameters. Int. J. Curr. Microbiol. App. Sci, 7 (9): 3575-3584.

[11] Shilpa. D., K. L. Naik and B. B. Hosetti. 2018. Population dynamics of yellow stem borer Scirphophaga incertulas (Walker) on rice (Oryza sativa): Using sex pheromone trap at Shimoga District, Karnataka. Intern. J. Eng. Sci. Invention. 7: $17-22$.

[12] Mishra, M. K. and R. C. Sharma. 2012. Validation of pheromone based IPM module against yellow stem borer Scirpophaga incertulas Walker in basmati rice. Indian $J$. Entomol. 74 (4): 352-354.

[13] Satpathi, C. R., A. M. Raut and K. Krishnaiah. 2016. Auto confusion technology-An innovative and novel method of use of pheromone for management of rice yellow stem borer Scirpophaga incertulas (Walker) in Eastern India. Intern. J. Plant, Ani. and Envi. Sci. 7 (1). 1-10.

[14] Katti, G., I. C. Pasalu, N. R. G. Varma, K. Krishnaiah. 2001a. Integration of pheromone mass trapping and biological control for management of yellow stem borer and leaf folder in rice. Indian J. Entomol. 63: 325-328.

[15] Dash A. N., S. K. Mukherjee and B. K. Sontakke. 2006 Evaluation of integrated pest management (IPM) components on irrigated rice. Indian J. Entomol. 68: 171-173.
[16] Kumar, A., A. K. Misra, P. Satyanarayana and J. Kumar. 2015. Population dynamics and management of yellow stem borer (Scirpophaga incertulas Walker) with insect sex-pheromone trap. Intern. J. Plant Prot. 8: 157-161.

[17] Surendra, P., K. Archana and R. K. Jha. 2016. Assessment of pheromone-based IPM module against yellow stem borer, Scirpophaga incertulas (Walker) in paddy crop. Intern. J. Agri. Sci. 8 (51): 2369-2371.

[18] Justin, C. G. L and G. Preetha. 2013. Seasonal incidence of rice yellow stem borer, Scirphphaga incertulas (Walker) in Tamil Nadu, Indian J. Entomol. 75: 109-112.

[19] Gomez. K. A. and A. Gomez. 1983. Statistical procedures for agricultural research. John Wiley, New York (Second Edition). $680 \mathrm{pp}$.

[20] Santiago, G. C., G. S. Rillon, and R. C. Joshi. 2006. Evaluation of yellow rice stem borer (Scirpophaga incertulas) six pheromone trap at Philrice Central Experiment Station [Philippines]. Crop Protection Div. Philippine Entomologist, 20 (2). $191 \mathrm{pp}$.

[21] Nandagopal, V., T. V. Prasad, M. V. Dharmrajsini Jethwa, V. G. Koradia and H. V. Patel. 2010. Evaluation of pheromone traps against brinjal fruit and shoot borer, Leucinodes orbonalis Guenee. Indian J. Entomol. 72: 7-10.

[22] Sithanantham S., M. Prabakaran, S. Judy, R. Kandasamy, M. Raju, C. Thamarai Chelvi and R. Kalyanakumar. 2016. Improved pheromone trap system for two sugar cane borers and seasonal trap monitoring of borer in relation to local climatic factors in factory areas of south India. SISSTA. Sugar Journal. 46. pp: 177-186.

[23] Sithanantham, S., M. Prabakaran, B. Bhavani, K. Jhansi, P. Vijayaprasd, V. Babu, V. V. Punnarao, N. Kannanraja. 2019. Multi-location test of alternative pheromone trap designs for sugarcane early shoot borer in south India. Sugar Tech. 21: 1-7

[24] Amsa T., M. Prabakaran, S. Sithanantham and M. Nalini. 2019. Pheromone trapping of brinjal fruit and shoot borer: Male orientation and spatial distribution. Indian. J. Entomol. 81 (1): 134-136.

[25] Anand Prakash, J. S. Bentur, M. Srinivas Prasad, R. K. Tanwar, O. P. Sharma, Someshwar Bhagat, Mukesh Sehgal, S. P. Singh, Monika Singh, C. Chattopadhyay, S. N. Sushil, A. K Sinha, Ram Asre, K. S. Kapoor, K. Satyagopal, and P. Jeyakumar. 2014. Integrated pest management package for rice. National Centre for Integrated Pest Management. New Delhi, India. 43 pp.

[26] Prabakaran, M., S. Doureisamy, V. Bhasker, M. Ravi, S. Sithanantham, and K Ramaraj. 2019. Waterless pheromone trap-efficient alternative to water basin trap for sugarcane early shoot borer. Indian J. Entomol. 81 (1): 137-139. 